University of Nebraska - Lincoln

DigitalCommons@University of Nebraska - Lincoln

2012

\title{
Analysis of Phase Separation in High Performance PbTe-PbS Thermoelectric Materials
}

\author{
Steven N. Girard \\ Northwestern University, steven.n.girard@gmail.com \\ Klaus Schmidt-Rohr \\ lowa State University, srohr@iastate.edu \\ Thomas C. Chasapis \\ Northwestern University \\ Euripides Hatzikraniotis \\ Aristotle University of Thessaloniki, evris@physics.auth.gr \\ B. Njegic \\ Ames Laboratory U.S. DOE, bnjegic@ameslab.gov \\ See next page for additional authors
}

Follow this and additional works at: https://digitalcommons.unl.edu/usdoepub

Part of the Bioresource and Agricultural Engineering Commons

Girard, Steven N.; Schmidt-Rohr, Klaus; Chasapis, Thomas C.; Hatzikraniotis, Euripides; Njegic, B.; Levin, E. M.; Rawal, A.; Paraskevopoulos, Konstantinos M.; and Kanatzidis, Mercouri G., "Analysis of Phase Separation in High Performance PbTe-PbS Thermoelectric Materials" (2012). US Department of Energy Publications. 324.

https://digitalcommons.unl.edu/usdoepub/324

This Article is brought to you for free and open access by the U.S. Department of Energy at DigitalCommons@University of Nebraska - Lincoln. It has been accepted for inclusion in US Department of Energy Publications by an authorized administrator of DigitalCommons@University of Nebraska - Lincoln. 


\section{Authors}

Steven N. Girard, Klaus Schmidt-Rohr, Thomas C. Chasapis, Euripides Hatzikraniotis, B. Njegic, E. M. Levin, A. Rawal, Konstantinos M. Paraskevopoulos, and Mercouri G. Kanatzidis 


\title{
Analysis of Phase Separation in High Performance PbTe-PbS Thermoelectric Materials
}

\author{
Steven N. Girard, Klaus Schmidt-Rohr, Thomas C. Chasapis, Euripides Hatzikraniotis, \\ B. Njegic, E. M. Levin, A. Rawal, Konstantinos M. Paraskevopoulos, \\ and Mercouri G. Kanatzidis*
}

Phase immiscibility in PbTe-based thermoelectric materials is an effective means of top-down synthesis of nanostructured composites exhibiting low lattice thermal conductivities. $\mathrm{PbTe}_{1-x} \mathrm{~S}_{x}$ thermoelectric materials can be synthesized as metastable solid solution alloys through rapid quenching. Subsequent post-annealing induces phase separation at the nanometer scale, producing nanostructures that increase phonon scattering and reduce lattice thermal conductivity. However, there has yet to be any study investigating in detail the local chemical structure of both the solid solution and nanostructured variants of this material system. Herein, quenched and annealed (i.e., solid solution and phase-separated) samples of PbTe-PbS are analyzed by in situ high-resolution synchrotron powder X-ray diffraction, solid-state ${ }^{125} \mathrm{Te}$ nuclear magnetic resonance (NMR), and infrared (IR) spectroscopy analysis. For high concentrations of PbS in PbTe, e.g., $x>16 \%$, NMR and IR analyses reveal that rapidly quenched samples exhibit incipient phase separation that is not detected by state-of-the-art synchrotron X-ray diffraction, providing an example of a PbTe thermoelectric "alloy" that is in fact phase inhomogeneous. Thermally-induced $\mathrm{PbS}$ phase separation in $\mathrm{PbTe}-\mathrm{PbS}$ occurs close to $200{ }^{\circ} \mathrm{C}$ for all compositions studied, and the solubility of the PbS phase in $\mathrm{PbTe}$ at elevated temperatures $>500{ }^{\circ} \mathrm{C}$ is reported. The findings of this study suggest that there may be a large number of thermoelectric alloy systems that are phase inhomogeneous or nanostructured despite adherence to Vegard's Law of alloys, highlighting the importance of careful chemical characterization to differentiate between thermoelectric alloys and composites.

\section{Introduction}

Thermoelectric materials hold promise as environmentally friendly heat-to-electric power generators, but are limited by low efficiencies. The efficiencies of thermoelectric materials are related to the thermoelectric figure of merit (ZT). For conventional bulk thermoelectric materials, such as $\mathrm{Bi}_{2} \mathrm{Te}_{3}, \mathrm{PbTe}$, and $\mathrm{SiGe}$, values of $\mathrm{ZT}$ have been limited to approximately $1 .^{[1-5]}$ Recently, research toward increasing the $\mathrm{ZT}$ of thermoelectric materials has succeeded using the concept of nanostructuring. By incorporating nanostructures, the lattice thermal conductivity $\left(\kappa_{\text {lat }}\right)$ may be significantly reduced through phonon scattering, preferably without a significant reduction in carrier mobility, resulting in enhanced ZT. ${ }^{[1,4]}$ Reductions in lattice thermal conductivity have been observed in high-ZT thin-film materials, ${ }^{[6,7]}$ nanomaterials, ${ }^{[8,9]}$ and nanostructured bulk materials. ${ }^{[10]}$ In particular, nanostructured bulk materials hold promise because their apparent ease in scalability and synthesis makes them immediately attractive for commercial fabrication of thermoelectric devices in the very near future.
Dr. S. N. Girard, Dr. T. C. Chasapis

Department of Chemistry

Northwestern University

Evanston IL 60208, USA

Prof. K. Schmidt-Rohr

Department of Chemistry

lowa State University

Ames, IA 50011, USA

Prof. K. Schmidt-Rohr, Dr. B. Njegic, Dr. E. M. Levin, Dr. A. Rawal

Division of Materials Sciences and Engineering

Ames Laboratory U.S. DOE, Ames, IA 50011, USA

Dr. T. C. Chasapis, Dr. E. Hatzikraniotis,

Prof. K. M. Paraskevopoulos

Physics Department

Aristotle University of Thessaloniki

GR- 54124, Thessaloniki, Greece
Prof. M. G. Kanatzidis

Department of Chemistry

Northwestern University

Evanston IL 60208, USA

E-mail: m-kanatzidis@northwestern.edu

Prof. M. G. Kanatzidis

Materials Science Division

Argonne National Laboratory U.S. DOE

Argonne, IL 60439, USA

DOI: 10.1002/adfm.201201944 
Recent attempts to control the formation of nanostructures in bulk thermoelectric materials involve a microstructure engineering approach whereby phase-separation processes are manipulated to generate a nanoscale second phase that is embedded within the parent thermoelectric material. This has been demonstrated in $\mathrm{PbTe}$ and GeTe systems using a variety of approaches, including precipitation, ${ }^{[11-13]}$ nucleation and growth and spinodal decomposition, ${ }^{[14-16]}$ eutectic, ${ }^{[17-20]}$ and matrix encapsulation methods. ${ }^{[21,22]}$ In each of these examples, the parent "matrix" material and second minor phase must be judiciously chosen considering phase stability and compatibility in thermoelectric properties. Many of these systems utilize natural phase separation and precise thermal treatment to selectively cause the minor phase to precipitate as nanostructures $<100 \mathrm{~nm}$. Some systems, such as those exhibiting reversible phase-separation phenomena, ${ }^{[14-16]}$ are especially interesting because the nucleation and coarsening of minor phases may be systematically controlled by thermal treatment.

We recently showed that the $\mathrm{PbTe}_{1-x} \mathrm{~S}_{x}$ (alternatively, PbTe$\mathrm{PbS} \mathrm{x} \%)$ thermoelectric materials system may be thermally manipulated to selectively create solid-solution and nanostructured analogues. ${ }^{[23]}$ From these studies, it was found that the reduction in lattice thermal conductivity was more pronounced in the nanostructured samples compared with the solid solutions, resulting in enhanced ZT. This system is one of the highest performing thermoelectric materials to date, with values of ZT from 1.5 to 1.8 at $700-800 \mathrm{~K} .{ }^{[24]}$ These large values of ZT are caused either directly or in part by low lattice thermal conductivity, produced by phonon scattering at the interfaces of coherent $\mathrm{PbS}$ nanostructures embedded within the PbTe matrix. We have previously shown that solid solutions of $\mathrm{PbTe}-\mathrm{PbS} 8 \%$ measured from room temperature to $700 \mathrm{~K}$ exhibit nanoscale phase separation and a significant reduction in lattice thermal conductivity. ${ }^{[23]}$ The $\mathrm{PbTe}-\mathrm{PbS}$ system exhibits a miscibility gap where thermodynamic phase separation will occur by metastable nucleation and growth or unstable spinodal decomposition processes; see Figure 1 a. ${ }^{[25-29]}$ Nucleation and growth and spinodal decomposition phase transformations occur because of the distinct curvature in the Gibbs free energy $(G)$ curve for a given isotherm over the composition range $\mathrm{x}$ as the material transforms to reduce the overall free energy of the system. ${ }^{[30]}$

In the nucleation and growth region, normally at the outer extremes of the composition range, the free energy curve has positive curvature (i.e., opens "upward" like the letter $u$ ) expressed as $\partial^{2} \mathrm{G} / \partial \mathrm{x}^{2}>0$. This means small variations in composition in this range lead to an increase in free energy. Rapidly cooled solid solutions are thermodynamically metastable, and the free energy can only be decreased if nuclei with a drastically different composition are generated, typically by thermal treatment. Once nuclei are formed, "down-hill" diffusion causes particle coarsening through the desaturation of atoms of the minor phase in the surrounding matrix. Conversely, spinodal decomposition occurs toward the inner part of the composition range, where the free energy curve has negative curvature (i.e., opens "downward" like the letter n) expressed as $\partial^{2} \mathrm{G} / \partial \mathrm{x}^{2}$ $<0$. Because small changes in composition reduce the free energy, the material will immediately form minute compositional fluctuations that will coarsen through an 'uphill' diffusion process. This means that rapidly cooled solid solutions are

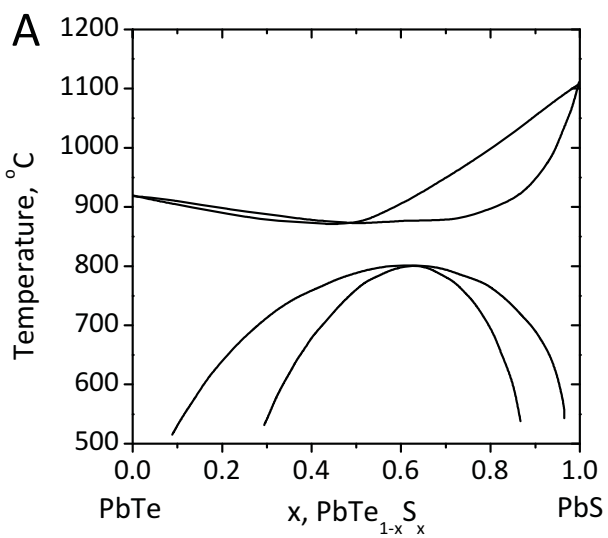

B
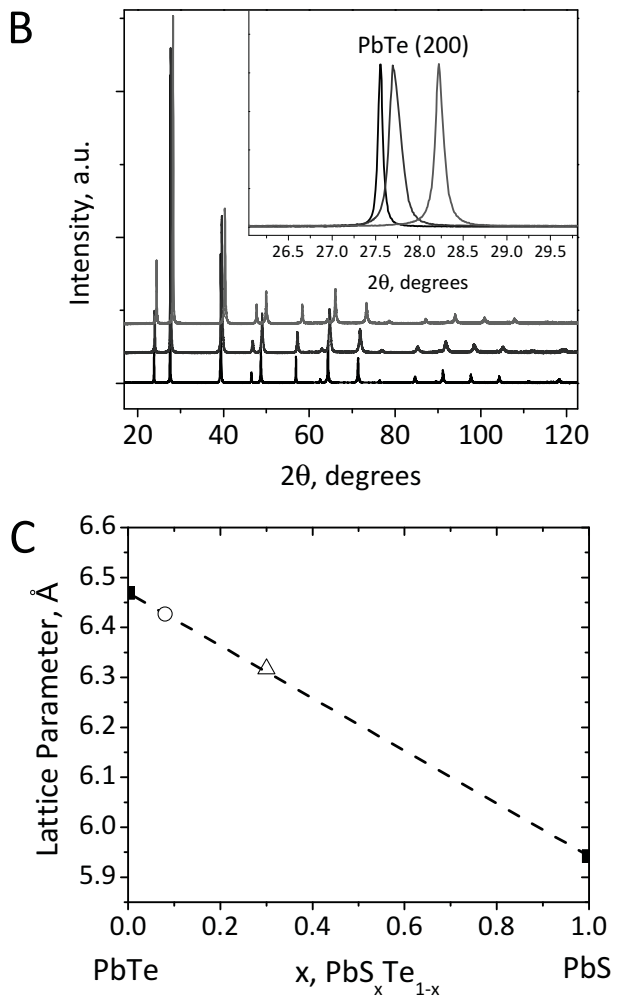

Figure 1. a) Experimentally derived PbTe-PbS phase diagram, adapted with permission. ${ }^{[29]}$ b) High-resolution PXRD of quenched PbTe (bottom), $\mathrm{PbTe}-\mathrm{PbS} 8 \%$ (middle), and PbTe-PbS 30\% (top). The inset shows the contraction of the PbTe lattice for the (200) Bragg reflection moving from quenched $\mathrm{PbTe}$ (leftmost peak), PbTe-PbS $8 \%$ (middle peak), and $\mathrm{PbTe}-\mathrm{PbS} 30 \%$ (rightmost peak). Rapidly quenched samples of PbTe-PbS create a single-phase cubic phase (space group $\mathrm{Fm} 3 \mathrm{~m}$ ) with a homogeneous distribution of $S$ and $T e$ at the cationic sites of the crystal lattice. c) Lattice parameters of samples from b) showing nearly ideal solid-solution alloying of quenched PbTe-PbS $8 \%$ (open circle) and PbTe-PbS 30\% (open triangle).

thermodynamically unstable and should spontaneously decompose into a two-phase mixture regardless of thermal treatment.

To date, there has yet to be a systematic study addressing the thermodynamic and kinetic phase interactions within the pseudo-binary PbTe-PbS system. Ideally, a firm understanding 
of the temperatures of nanoparticle nucleation may enable the engineering of the size and relative dispersion of $\mathrm{PbS}$ nanoparticles within $\mathrm{PbTe}$, and correspondingly tune the thermoelectric properties. Recently, Ikeda et al. ${ }^{[31,32]}$ and Gorsse et al. ${ }^{[15]}$ have reported systematic annealing studies for PbTe-based materials, wherein the coarsening of microstructures may be controlled by thermal treatment. However, for such phase immiscible systems the nanostructured phase will also dissolve in the matrix at sufficiently high temperatures. The exact temperatures where this occurs should be determined in order to take full advantage of nanostructures to reduce lattice thermal conductivity.

In this paper, we investigate the chemical phase stability in the PbTe-PbS thermoelec-
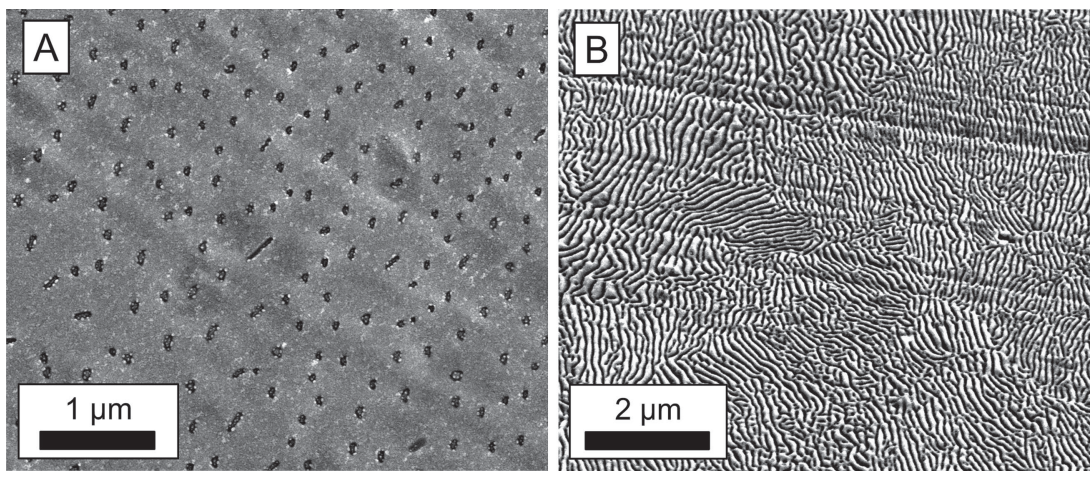

Figure 2. Microstructure of phase-separated (annealed) PbTe-PbS of different compositions: a) $8 \%$ and b) $30 \%$. The $30 \%$ composition phase separates by spinodal decomposition, producing an interconnected labrythine network of PbS (dark regions) throughout the PbTe matrix, while nucleation and growth in the $8 \%$ composition produces spherical nuclei of PbS (dark regions) within the PbTe matrix. tric system using a variety of spectroscopic and physiochemical analyses to understand the formation of nanostructures. It has already been demonstrated that phaseseparated nanodomains in $\mathrm{PbTe}-\mathrm{PbS}$ produce low values of lattice thermal conductivity. ${ }^{[16,23,24]}$ Herein, we analyze quenched and annealed (i.e., solid solution and phase-separated) samples of $\mathrm{PbTe}-\mathrm{PbS}$ by in situ high-resolution synchrotron powder X-ray diffraction (PXRD), solid-state ${ }^{125}$ Te nuclear magnetic resonance (NMR), and infrared (IR) spectroscopy analysis. For high concentrations of $\mathrm{PbS}$ in $\mathrm{PbTe}(>16 \%)$, we show that rapidly quenched samples exhibit incipient phase separation, despite adherence to Vegard's law of alloys as determined by X-ray diffraction, providing another example of a seemingly PbTe thermoelectric "alloy" that is in fact phase inhomogeneous. ${ }^{[33]} \mathrm{We}$ show that thermally-induced $\mathrm{PbS}$ phase separation in $\mathrm{PbTe}-$ $\mathrm{PbS}$ occurs close to $200{ }^{\circ} \mathrm{C}$ and report the solubility of $\mathrm{PbS}$ in $\mathrm{PbTe}$ at elevated temperatures $>500^{\circ} \mathrm{C}$. Many reports within the field of thermoelectrics and beyond have evidenced solid solutions by adherence to Vegard's law and simple X-ray characterization; this work emphasizes the importance of careful chemical and microstructural characterization that is paramount in adequately describing the differences between thermoelectric materials asserted to be either alloyed or nanostructured.

\section{Results and Discussion}

\subsection{High-Resolution PXRD of PbTe-PbS}

We initially needed to verify that $\mathrm{PbTe}-\mathrm{PbS}$ materials could successfully generate genuine solid-solution alloys upon rapid quenching directly from the melt. We specifically chose the $\mathrm{PbTe}-\mathrm{PbS} 8$ and $30 \%$ compositions for several reasons: 1) both exhibit low lattice thermal conductivity, presumably from nanostructuring;[16] 2) they phase separate by differing processes (nucleation and growth and spinodal decomposition, respectively); 3) both compositions have been extensively studied in our research group; ${ }^{[23,34]}$ and 4) given limited beam time at the Advanced Photon Source (APS), we preferentially chose to closely study these compositions. High-resolution powder X-ray diffraction of rapidly cooled PbTe-PbS 8 and $30 \%$ are shown in Figure $1 \mathrm{~b}$. The lattice parameter (d-spacing) of the PbTe matrix monotonically decreases with increasing $\mathrm{PbS}$ incorporation, and the samples obey Vegard's law (Figure 1c).

The microstructure examined by scanning electron microscopy (SEM) of as-quenched samples of undoped PbTe-8\% $\mathrm{PbS}$ and $30 \% \mathrm{PbS}$ does not exhibit any large $\mathrm{PbS}$ precipitates. Once annealed at $500{ }^{\circ} \mathrm{C}$ for $72 \mathrm{~h}$, the samples undergo clear $\mathrm{PbS}$ phase separation. The $\mathrm{PbTe}-\mathrm{PbS} 8 \%$ sample shows mostly spherical precipitates with an average diameter of $100 \mathrm{~nm}$ (Figure 2 a). As a result of the nucleation and growth phase transformation, mostly spherical particles are observed. Conversely, the $\mathrm{PbTe}-\mathrm{PbS} 30 \%$ sample exhibits a labyrinthine network structure of interconnected $\mathrm{PbS}$-rich regions (Figure $2 \mathrm{~b}$ ). The slight compositional fluctuations that coarsen with time as a result of spinodal decomposition result in interconnected rodlike lamellar structures. The average width of the $\mathrm{PbS}$ precipitates is $\approx 100 \mathrm{~nm}$ and they can extend microns in length. Energy dispersive X-ray spectroscopy (EDS) verified the presence of the $\mathrm{PbS}$ phase in the annealed samples. However, elemental analysis by EDS was unsuccessful for the solid solution samples because of the close overlap in the $\mathrm{M}$ and $\mathrm{K}$ lines of $\mathrm{Pb}$ and $\mathrm{S}$, respectively. We did not include any transmission electron microscopy (TEM) in this study, as it has been reported in detail previously. ${ }^{[23,34]}$

In order to better understand the onset of nanostructure generation, the solid-solution $\mathrm{PbTe}-\mathrm{PbS} 8$ and 30\% samples were initially analyzed by synchrotron high-resolution PXRD using a high-temperature blower heating at $5{ }^{\circ} \mathrm{C} / \mathrm{min}$. The results are shown in Figure 3. For the $\mathrm{PbTe}-\mathrm{PbS} 8 \%$ sample, $\mathrm{PbS}$ reflections become visible above $250{ }^{\circ} \mathrm{C}$ (Figure 3a). The region of immiscibility is roughly in the range of 200 to $500{ }^{\circ} \mathrm{C}$. The temperature of dissolution of $\mathrm{PbS}$ at approximately $500{ }^{\circ} \mathrm{C}$ is in close agreement with the phase diagram published by Leute, reproduced in Figure 1a. ${ }^{[29]}$ For the PbTe-PbS 30\% sample, a significant precipitation of $\mathrm{PbS}$ is observed between 250 and $700{ }^{\circ} \mathrm{C}$ (Figure $3 \mathrm{c}$ ). Additionally, above $\approx 550{ }^{\circ} \mathrm{C}$ the movement of the sample from the spinodal to the nucleation and growth region (see Figure 1a) results in increased dissolution of S into 

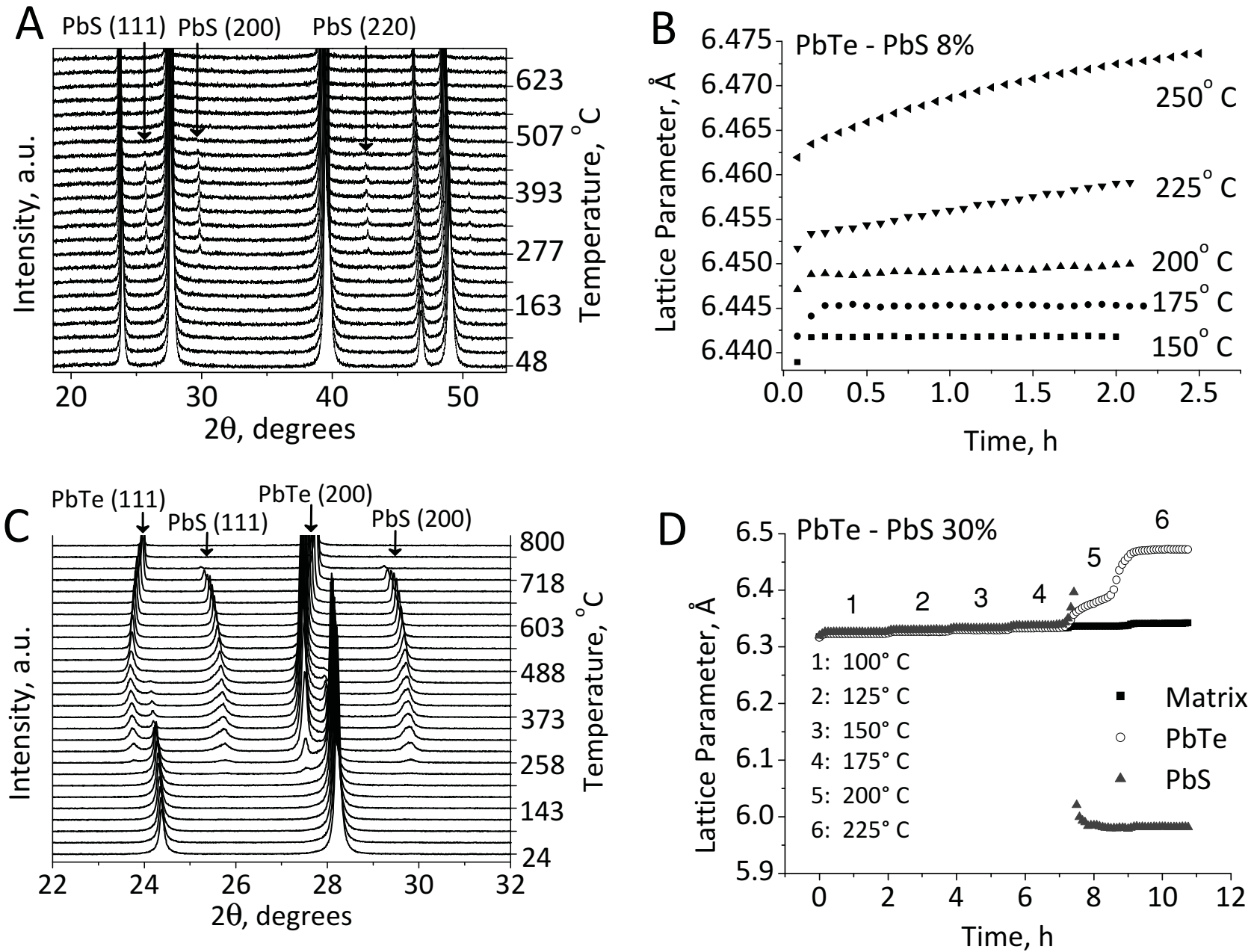

Figure 3. High temperature phase stability of PbTe-PbS. a) In situ high-temperature PXRD of PbTe-PbS $8 \%$ solid-solution alloys. The precipitation of $\mathrm{PbS}$ is evidenced by the appearance of $\mathrm{PbS}(111),(200)$, and (220) reflections between 200 and $500{ }^{\circ} \mathrm{C}$. At temperatures $>500{ }^{\circ} \mathrm{C}$, the $\mathrm{PbS}$ redissolves into the $\mathrm{PbTe}$ matrix, re-forming a solid solution. b) In situ high-temperature PXRD of $\mathrm{PbTe}-\mathrm{PbS} 30 \%$ solid-solution alloys. The precipitation of PbS is evidenced as in Figure 4. The higher $\mathrm{PbS}$ concentration produces a region of immiscibility between 250 and $750{ }^{\circ} \mathrm{C}$. At temperatures $>750{ }^{\circ} \mathrm{C}$, the $\mathrm{PbS}$ redissolves into the $\mathrm{PbTe}$ matrix, re-forming a solid solution. $\mathrm{c}$ ) Rietveld refinements of lattice parameters for annealing studies of $\mathrm{PbTe}$ matrix in $\mathrm{PbTe}-\mathrm{PbS} 8 \%$, and d) $\mathrm{PbS}_{1-x} \mathrm{Te}_{x}$ solid solution, $\mathrm{PbTe}$, and $\mathrm{PbS}$ phases in $\mathrm{PbTe}-\mathrm{PbS} 30 \%$. Each sample was heated for two hours at the temperatures indicated. For both samples, significant PbS precipitation is initiated at temperatures at and above $200^{\circ} \mathrm{C}$; in (c) this is evidenced by a slight increase in the third annealing step, and in (d) this is evidenced by the sudden appearance of $\mathrm{PbS}$ and $\mathrm{PbTe}$ reflections. The slight increase in PbS lattice parameter at the onset of precipitation is an artifact of poor refinement caused by the minute $\mathrm{PbS}$ peak generated at the onset of precipitation.

$\mathrm{PbTe}$ and $\mathrm{Te}$ into $\mathrm{PbS}$, contracting the $\mathrm{PbTe}$ and expanding the $\mathrm{PbS}$ lattices, in agreement with the lever rule. We show that $\mathrm{PbTe}-\mathrm{PbS}$ behaves ideally, and that we may selectively generate solid-solution alloys and phase-separated samples depending on thermal treatment.

In order to more precisely determine the temperature of phase separation for PbTe-PbS 8 and 30\%, we performed selective annealing studies of the samples around the lower temperature of immiscibility. For PbTe-PbS $8 \%$, we heated in five $25^{\circ}$ steps from $150-250{ }^{\circ} \mathrm{C}$, while for PbTe-PbS $30 \%$, we heated in six $25^{\circ} \mathrm{C}$ steps from $100-225^{\circ} \mathrm{C}$ (Figure $3 \mathrm{~b}, \mathrm{~d}$ ). At each temperature step, the sample was held for two hours while repeated diffraction scans were collected. We then analyzed the diffraction patterns by Rietveld refinements, to accurately determine the effect of the annealing temperatures without thermal expansion of the lattice or thermal smear. For PbTe-PbS 8\%, we indexed only major peaks of PbTe because the PbS peaks were too small to accurately refine. The PbTe matrix shows monotonic thermal expansion of the lattice for the first two annealing steps without any change in lattice parameter over time (Figure 3b). At the $200{ }^{\circ} \mathrm{C}$ annealing step, a slight but perceptible increase of the lattice parameter is observed over time. This shows that precipitation of $\mathrm{PbS}$ in $\mathrm{PbTe}-\mathrm{PbS} 8 \%$ solid-solution alloys is initiated between 175 and $200{ }^{\circ} \mathrm{C}$, in close agreement with our previous in situ properties measurements. ${ }^{[23]}$ At higher temperatures, the lattice parameter increases more rapidly as a consequence of enhanced $\mathrm{PbS}$ dissolution within the PbTe matrix at elevated temperatures. For $\mathrm{PbTe}-\mathrm{PbS} 30 \%$, the precipitation of distinct 
$\mathrm{PbS}$ and $\mathrm{PbTe}$ phases is detected almost immediately after $200{ }^{\circ} \mathrm{C}$ has been reached (Figure 3d). For both samples, the kinetic barriers to significant phase separation appear to be overcome at temperatures close to $200{ }^{\circ} \mathrm{C}$. In future studies, this information may be utilized to create systematically sizecontrolled nanostructures by limiting the coarsening of the particles following nucleation.

\section{2. ${ }^{125} \mathrm{Te}$ NMR of Solid-Solution PbTe-PbS}

In order to gain a deeper understanding of the chemical structure of quenched and of annealed $\mathrm{PbTe}-\mathrm{PbS}$ materials, we conducted ${ }^{125} \mathrm{Te}$ NMR to determine the local structure of the PbTe-rich matrix. ${ }^{[35-39]}$ We synthesized $\mathrm{PbTe}-\mathrm{PbS} 4,8,16,30$, and $50 \%$ samples that had been quenched to generate solid-solution alloys, and then annealed to phase separate. Figure 4 shows the ${ }^{125} \mathrm{Te}$ NMR spectra of the solid-solution materials. At low sulfur concentrations, the major peak is observed near $-1850 \mathrm{ppm}$, close to the resonance position of $\mathrm{PbTe},{ }^{[35]}$ as expected. Additionally, there are smaller peaks just to the right of the main signal that successively grow in intensity with increasing $\mathrm{PbS}$ concentration, $x$. These must be attributed to sulfur atoms producing a chemical shift at a nearby ${ }^{125} \mathrm{Te}$ nucleus, with an increment of approximately -140 ppm per sulfur. They cannot be due to different Knight shifts (resulting from different charge carrier concentrations), since the $\mathrm{T}_{1}$ relaxation times of all the signals are similar; a change in Knight shift by -140 ppm in $\mathrm{PbTe}$ corresponds to a change in $\mathrm{T}_{1}$ relaxation time by orders of magnitude. ${ }^{[35-37]}$ Furthermore, a peak position of $-2000 \mathrm{ppm}$ in PbTe due to Knight shift would indicate p-type doping, ${ }^{[36]}$ while the present samples are $n$-type semiconductors.

In the $\mathrm{NaCl}$ structure of $\mathrm{PbTe}-\mathrm{PbS}$, each tellurium has 18 second neighbor sites on the Te sublattice that can be occupied by $\mathrm{S}$, see the inset in Figure 4. The probability of exactly $n$ sulfur neighbors out of $N$ total is given by a binomial formula, ${ }^{[39]}$

$\mathrm{P}_{x, N}(n)=x^{n}(1-x)^{N-n}\left(\begin{array}{l}N \\ n\end{array}\right)$

However, the bar graphs produced based on this formula with $N=18$, see Figure $4 \mathrm{a}$, do not provide good fits to the measured spectra. For instance, at small $x$, the fraction of Te with a $\mathrm{S}$ neighbor is $\mathrm{P}_{x, 18}(1)=18 x(1-x)^{17}$. For $x=0.04$, this predicts $\mathrm{P}_{x, 18}(1)=0.36$, while the area fraction under the corresponding peak is only 0.2 .

On the other hand, the NMR spectra are easy to explain if there are only up to $N=6$ (rather than 18 ) sulfur neighbors of
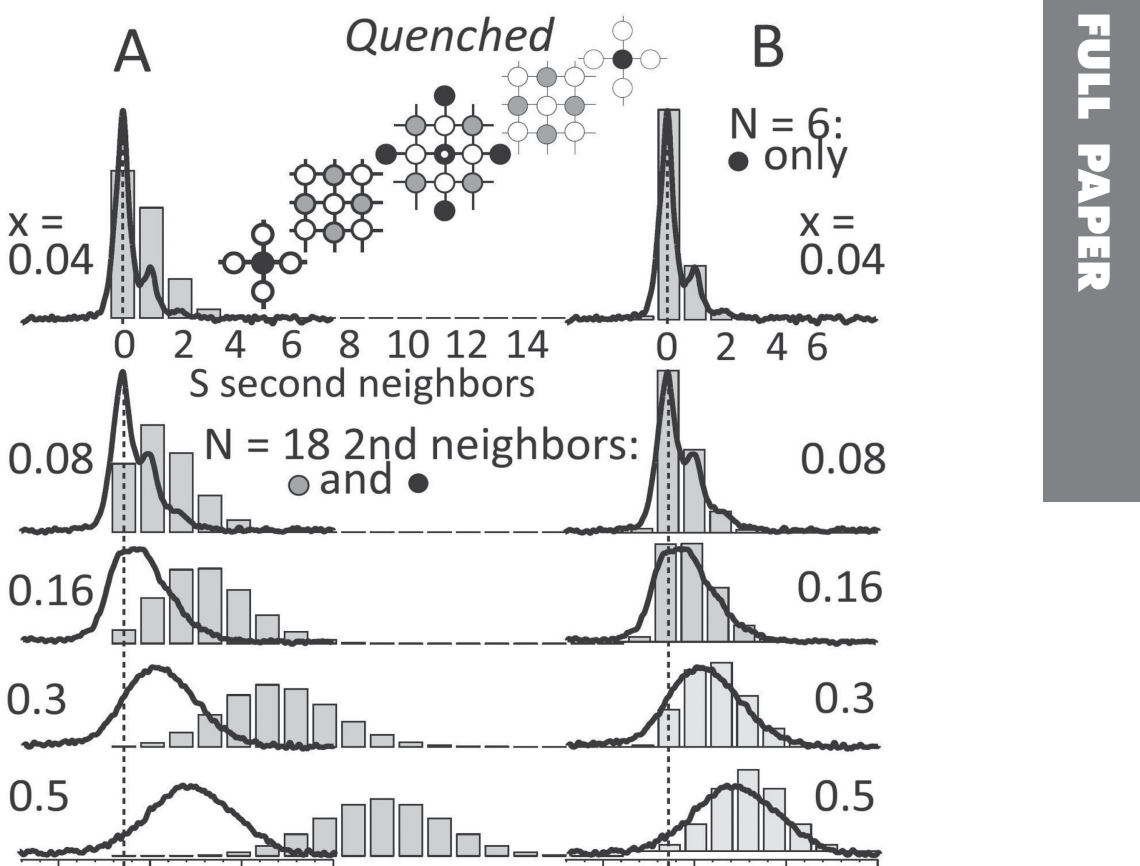

$-1500-2000-2500 \mathrm{ppm}-1500-2000-2500 \mathrm{ppm}$

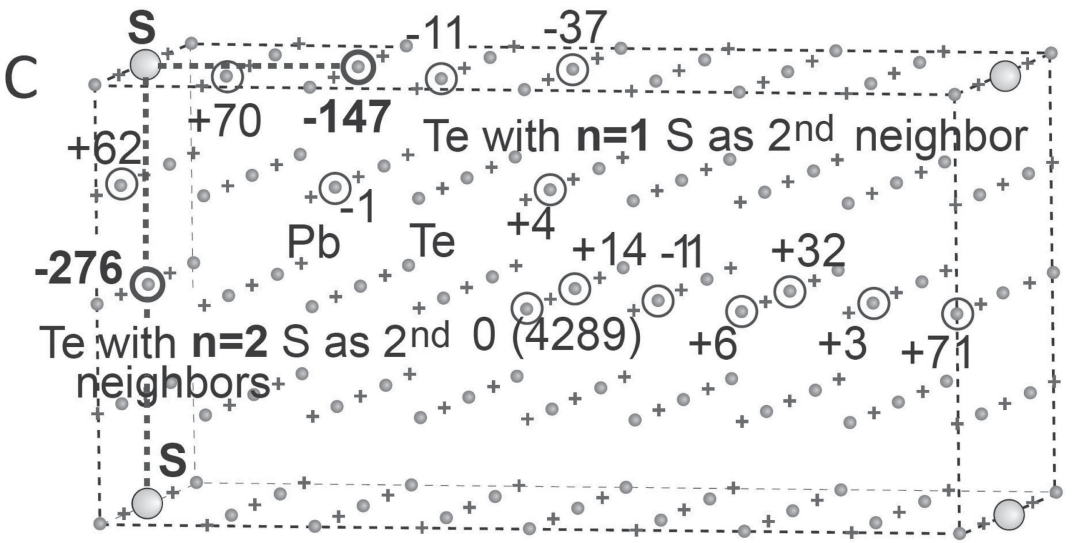

Figure 4. a,b) ${ }^{125} \mathrm{Te}_{\mathrm{NMR}}$ spectra of quenched $\mathrm{PbTe}_{1-x} \mathrm{~S}_{x}$ for $x=0.04,0.08,0.16,0.3$, and 0.5 . While the total area decreases with decreasing tellurium fraction, proportional to $(1-x)$, in the figure the spectra have been scaled to equal area for clarity. a) Spectra with overlaid bar graphs for up to $N=18$ sulfur neighbors producing chemical shifts of $-140 \mathrm{ppm}$. b) Same as (a) but with bar graphs for $\mathrm{N}=6$. Better fits for $x=0.3$ and 0.5 based on a spinodal-decomposition model are shown in Figure 5. First-order spinning sidebands included in these simulations produce two small extra bars on the left and right ends of the distribution. The inset (top center) shows five planes in the $\mathrm{NaCl}$ structure of PbTe with the 18 neighbors on the Te sublattice highlighted. The $\mathrm{N}=6$ sites apparently producing significant ${ }^{125} \mathrm{Te}$ chemical shift effects are marked by filled black circles. c) Calculated ${ }^{125} \mathrm{Te}$ isotropic chemical shifts in ppm with respect to the least perturbed tellurium atom (shielding given in brackets) in PbTe doped with a single sulfur atom, in a $\mathrm{PbTe}_{0.98} \mathrm{~S}_{0.02}$ unit cell optimized in $\mathrm{P} 4 / \mathrm{mmm}$ symmetry with calculated lattice parameters of $13.11 \AA \times 13.11 \AA \times 26.22 \AA$. The tellurium atoms are shown as small balls, lead atoms as crosses, and sulfur atoms as large balls.

a given tellurium that produce significant chemical shifts. An analysis in that light (see inset in Figure 4) shows that there are 6 second neighbors along two collinear bonds (filled black circles), and 12 with the two bonds at a right angle (filled gray circles), in the $\mathrm{NaCl}$ crystal structure. We interpret our data as showing that sulfur has strong effects on the ${ }^{125} \mathrm{Te}$ chemical shift only in the former $N=6$ sites. Figure $4 \mathrm{~b}$ shows bar graphs 
using $N=6$ in Equation (1), which provide good fits of the measured spectra up to $x=0.16$.

In order to provide a convincing confirmation of the hypothesis regarding the differential effect of different $\mathrm{Te}-\mathrm{Pb}-\mathrm{S}$ geometries, ${ }^{125} \mathrm{Te}$ NMR chemical shifts were calculated using density functional theory (DFT) for 64-atom and 128-atom unit cells of PbTe in which a single tellurium atom was substituted by sulfur (for technical details see the Supporting Information). Such ab initio DFT calculations can provide unique insights into the effects of dopants on ${ }^{125} \mathrm{Te}$ chemical shifts. A single $\mathrm{S}$ atom collinearly bonded to tellurium $\left({ }^{125} \mathrm{Te}-\mathrm{Pb}-\mathrm{S}\right)$ shows a shift of $-147 \mathrm{ppm}$, and two sulfur impurities in a collinear S-Pb${ }^{125} \mathrm{Te}-\mathrm{Pb}$-S arrangement cause a shift of $-276 \mathrm{ppm}$ (see Figure 4 and Figure S1 in the Supporting Information). These predicted ${ }^{125} \mathrm{Te}$ chemical shifts are in excellent agreement with the experimental data. When the $\mathrm{S}-\mathrm{Pb}$ bond is perpendicular to the $\mathrm{Pb}-\mathrm{Te}$ bond, the calculated shift is of smaller magnitude and opposite sign, even though this arrangement places S closest to the tellurium atom. Therefore, both calculated and experimental data identify a collinear ${ }^{125} \mathrm{Te}-\mathrm{Pb}-\mathrm{S}$ motif as producing the observed large negative change of about $-140 \mathrm{ppm}$ in the ${ }^{125} \mathrm{Te}$ chemical shift.

For solid-solution samples of $\mathrm{PbTe}-\mathrm{PbS} 30$ and $50 \%$, the maxima in the bar graphs simulated based on Equation (1) are to the right of the maxima in the experimentally observed spectra, see Figure $4 \mathrm{~b}$. This could mean that the PbTe-rich phase observed here contains less sulfur than the nominal composition; simulations with $x$ Te-rich $=0.26$ and 0.45 for nominal $x=0.3$ and 0.5, respectively, are shown in Figure 5a,b.

Good fits were also obtained for a model that approximates the results of the spinodal decomposition expected in this concentration region. This is consistent with the onset of spinodal decomposition deduced in the quenched $x=0.5$ sample from detailed analysis of scattering data. ${ }^{40]}$ Spinodal decomposition produces a periodic modulation of the composition in space. This results in a distribution of local compositions, but the main contributions are from the minimum and maximum

\section{A}

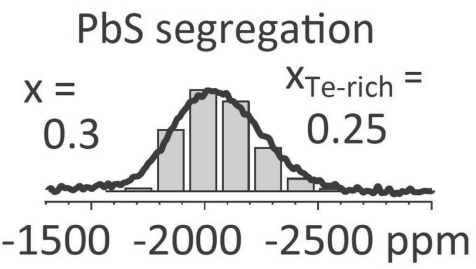

B

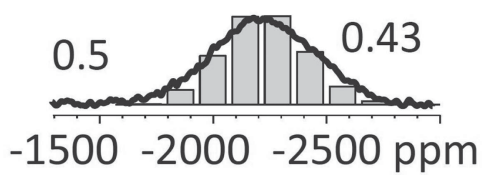

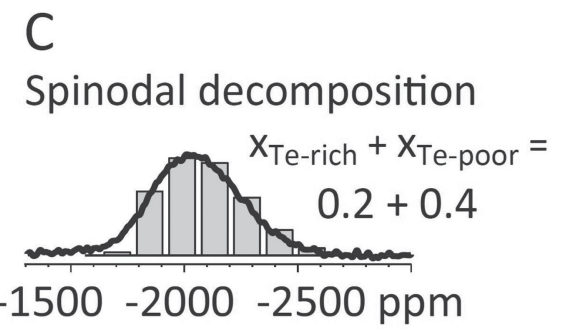

D

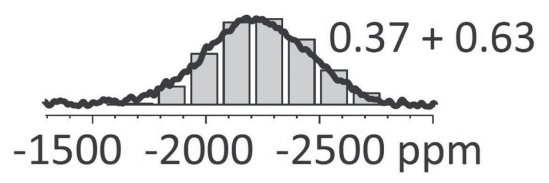

Figure 5. ${ }^{125} \mathrm{Te}$ NMR spectra of quenched $\mathrm{PbTe}_{1-x} \mathrm{~S}_{x}$ for $x=0.3$ and 0.5 compared with bar graphs from models assuming incipient phase separation. a,b): Model assuming segregation of nearly pure PbS, with negligible ${ }^{125} \mathrm{Te}$ NMR signal. c,d): Two-component model approximating spinodal decomposition. We find that the model presented in (c,d) provides a more accurate approximation of the composition, assuming that the early onset of spinodal decomposition has produced regions of inhomogeneous $\mathrm{PbTe}_{1-x} \mathrm{~S}_{x}$ alloying throughout the matrix. values of $x$. Therefore, we simulated the spectrum as resulting from two local environments of equal volume and compositions $x+\Delta x$ and $x-\Delta x$.

$$
\begin{aligned}
\mathrm{P}_{\mathrm{Sp}}(n)= & 1 / 2\left[\mathrm{P}_{x+\Delta x, 6}(n)(1-(x+\Delta x)) /(1-x)\right. \\
& \left.+\mathrm{P}_{x-\Delta x, 6}(n)(1-(x-\Delta x)) /(1-x)\right]
\end{aligned}
$$

where each component is weighted with its ${ }^{125} \mathrm{Te}$ NMR signal fraction, which is the fraction of Te, $(1-(x \pm \Delta x))$. Fits based on this model are shown in Figure $5 c$ and $d$. The shift in the maximum of $\mathrm{P}_{\mathrm{Sp}}(n)$ to the left is due to the larger Te signal of the Te-rich component, which has its maximum at lower $n$ (due to less $\mathrm{S})$. The width of $\mathrm{P}_{\mathrm{Sp}}(n)$ is larger since two unequal distributions are added together; this improves the quality of the fit for the nominal 30 and 50\% compositions.

The analysis provides clear evidence of incipient spinodal decomposition, increasing towards the center of the miscibility gap. The best fits give an indication of the amplitude $2 \Delta x$ to the composition difference between the Te-rich and -poor regions, but with significant uncertainties, not least ponent model used. Indeed, these samples exist as macroscale "solid solutions" with a largely homogeneous medium as evidenced by PXRD. However, by ${ }^{125} \mathrm{Te}$ NMR (and IR are slightly off-stoichiometry relative to the nominal concentrations of $\mathrm{PbTe}$ and $\mathrm{PbS}$.

\section{3. ${ }^{125} \mathrm{Te}$ NMR of Phase-Separated PbTe-PbS}

Figure 6 compares the ${ }^{125} \mathrm{Te}$ NMR spectra for solid-solution $\mathrm{PbTe}-\mathrm{PbS}$ in the left column (panels a-e) with corresponding spectra for annealed samples to the right (panels $\mathrm{f}-\mathrm{j}$ ). For small sulfur content $(x \leq 0.08)$, annealing changes the spectra only slightly. However, for $x>0.16$, the ${ }^{125} \mathrm{Te}$ spectra of the annealed samples exhibit a pattern similar to that of the quenched material with $x=0.08$; the best fit value is $x=0.065$. Since most Te is found in the Te-rich phase, the dominant signals in the ${ }^{125} \mathrm{Te}$ spectra are from this component. Thus, our spectra show that after annealing the PbTe-rich phase contains $7 \pm 1 \% \mathrm{~S}$, in good agreement with the lever rule applied to the phase diagram (Figure 1a). This shows that the assumption of Lin et al. ${ }^{[40]}$ that the $\mathrm{PbTe}$-rich phase is pure $\mathrm{PbTe}$ is not justified; apparently, analysis of the pair correlation function cannot detect substitution of Te by $\mathrm{S}$ at the $7 \%$ level in a multiphase material.

This composition, and even more directly the relatively minor spectral change upon annealing for $x=0.08$, means that in the annealed $x=0.08$ sample studied here only a small fraction of sulfur $(\Delta x=-0.01 \pm 0.015)$ may have precipitated to form micrometeror nanometer-scale inclusions of $\mathrm{PbS}(1 \pm$ 1 atom\% of $\mathrm{PbS}$ ). This is consistent with the 


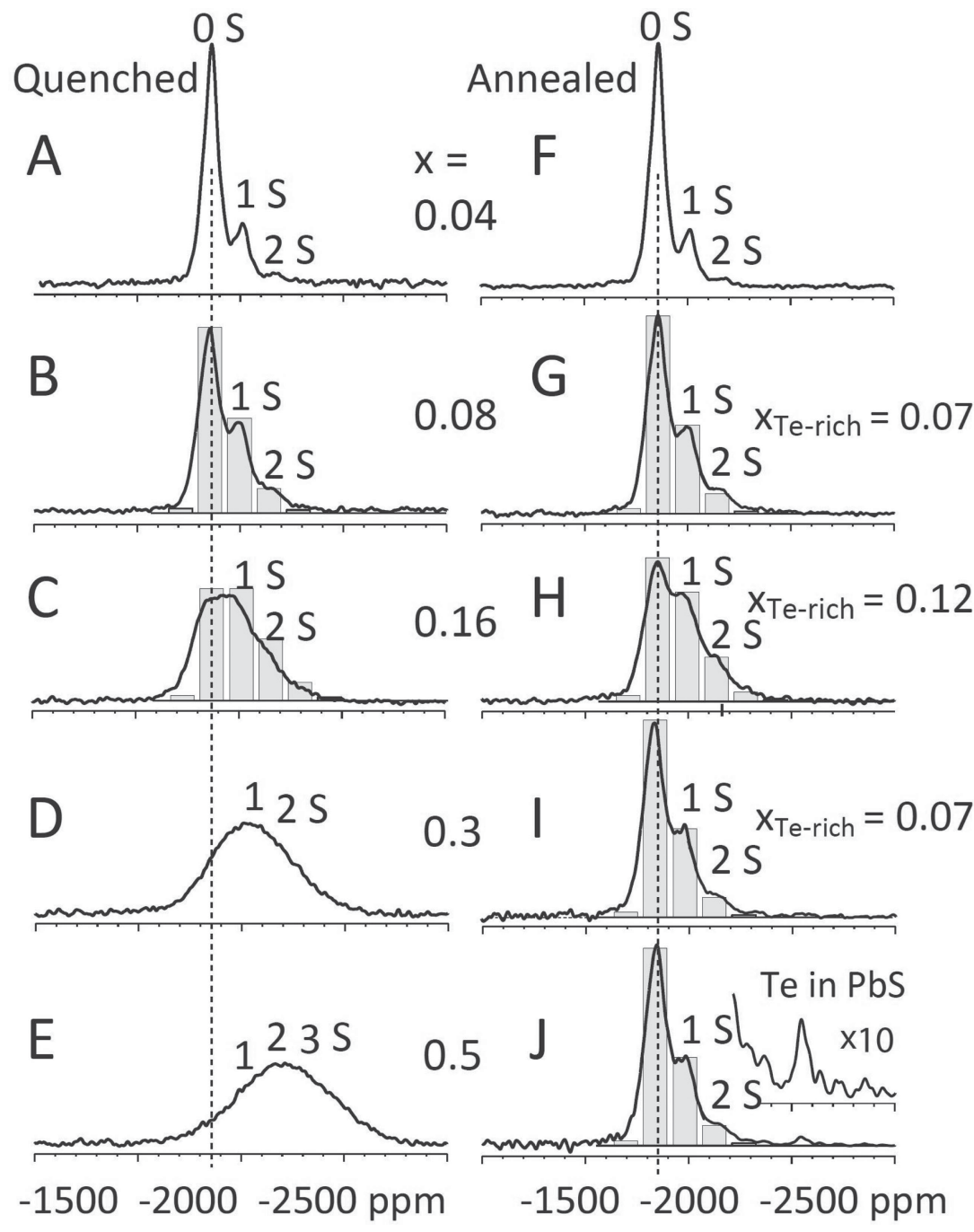

Figure 6. ${ }^{125} \mathrm{Te}$ NMR spectra of a-e) quenched and $\mathrm{f}-\mathrm{j}$ ) annealed $\mathrm{PbTe}-\mathrm{PbS}$ with compositions: $4,8,16,30$, and $50 \% \mathrm{PbS}$. The inset in (j) shows the sharp peak of Te in PbS near $-2550 \mathrm{ppm}$ with 10 -fold vertical expansion. While the total area decreases with decreasing tellurium fraction, proportional to $(1-x)$, in the figure the spectra have been scaled to equal area. transformations may result in a sample with increased $\mathrm{S}$ substitution by Te. Incomplete phase separation of the annealed $x=0.16$ material was also found by Lin et al. ${ }^{[40]}$

\subsection{Te in the PbS-Rich Phase}

Although the $\mathrm{PbS}$ phase is the minority phase in the samples studied here, it is interesting to examine its composition to determine $\mathrm{Te}$ incorporation; we refer to this as the PbSrich phase. The amount of $\mathrm{Te}$ in the $\mathrm{PbS}$-rich phase is small. Nevertheless, this dispersed tellurium is detectable as a small sharp peak in the ${ }^{125} \mathrm{Te}$ spectrum for $x=0.5$ in Figure $6 j$ at $\approx-2550 \mathrm{ppm}$, quite close to the position expected for $\mathrm{n}=6$ (i.e., near $-1840 \mathrm{ppm}+$ $6(-140 \mathrm{ppm})=-2680 \mathrm{ppm})$. Its area corresponds to $f_{\mathrm{d}}=2 \%$ of the total intensity. On this basis (see the Supporting Information for detailed calculations), we can conclude that the $\mathrm{PbS}$-rich phase contains about $2 \% \mathrm{PbTe}$, which is in good agreement with the phase diagram (Figure 1a) at the annealing temperature of $500^{\circ} \mathrm{C}$. In ${ }^{207} \mathrm{~Pb}$ NMR (not shown), attempts to resolve signals of $\mathrm{Pb}$ bonded to different numbers of $\mathrm{S}$ atoms, or just of the $\mathrm{PbS}$-rich phase, were not successful, due to line broadening that is larger than the $\approx 600$-ppm chemical shift difference between $\mathrm{PbTe}$ and $\mathrm{PbS}$. The line widths probably resulted from a range of Knight shifts (which reflect the local charge carrier concentration); due to a difference in the strength of the hyperfine couplings, the ${ }^{207} \mathrm{~Pb}$ Knight shifts in $\mathrm{PbTe}$ are about 25 times larger (in ppm) than those of ${ }^{125} \mathrm{Te} .{ }^{[41]}$
X-ray data, which show no peaks of PbS but only a peak shift in $2 \theta$ by $0.08^{\circ},{ }^{[23]}$ which appears to correspond to a sulfur content reduced by $\Delta x=-0.02$ to -0.03 (i.e., 2 to $3 \%$ ) in the PbTe-rich phase.

Our data are internally consistent with the following model, which in particular explains why the annealed $x=0.16$ sample shows a higher $\mathrm{S}$ content in the PbTe-rich phase than the other annealed samples. Namely, after annealing at $500{ }^{\circ} \mathrm{C}$ for $72 \mathrm{~h}$, $x=0.0(70 \pm 15)$ is the stable composition, which is quickly reached from within the region of spontaneous decomposition inside the spinodal curve (for the $x=0.3$ and $x=0.5$ samples). For $x=0.16$, which is in the intermediate region between nucleation-and-growth and spinodal decomposition, $x=0.12$ is observed as the average composition of the PbTe-rich component of our sample. Interestingly, this is also the sample composition that has been observed to have the largest $\mathrm{S}$ alloying in PbTe for our p-type $\mathrm{Na}$ doped $\mathrm{PbTe}-\mathrm{PbS}$ system. ${ }^{[24]} \mathrm{We}$ believe that the phase separation at the boundary of the two

\subsection{Infrared Reflectivity of PbTe-PbS}

We conducted infrared (IR) reflectivity studies of solid-solution and phase-separated $\mathrm{PbTe}-\mathrm{PbS} 8$ and 30\% samples at room temperature in order to better understand the chemical structure in light of the NMR results. Through excitations of optical and phonon modes, IR reflectivity can give us useful information regarding the sample composition: the as-obtained spectra and calculated fittings may provide information determining if the material is single or multiphase, the chemical composition of the phases, as well as phonon modes resulting from the chemical structure.

The IR reflectivity spectra of the $\mathrm{PbTe}-\mathrm{PbS}$ samples displayed in Figure 7 a show increased reflectivity values $\approx 90 \%$ in the low frequency range, and reflectivity minima in the frequency range $\approx 200-500 \mathrm{~cm}^{-1}$. For all the studied compositions the reflectivity spectra show features in the frequency range $\approx 100-160 \mathrm{~cm}^{-1}$. These features are associated with transverse 

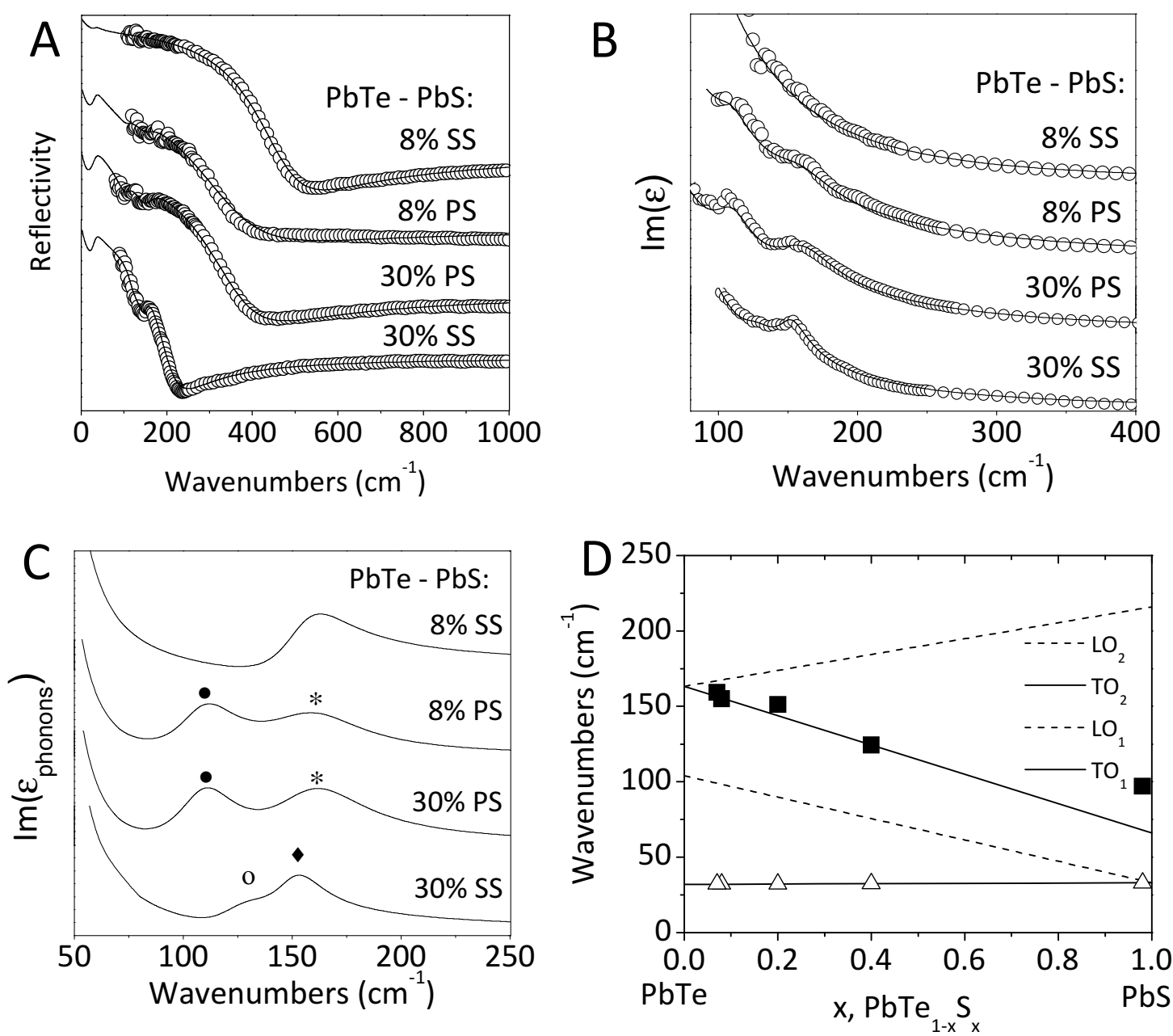

Figure 7. IR reflectivity of solid-solution and phase-separated PbTe-PbS $8 \%$ and PbTe-PbS $30 \%$ compositions. a) Experimental IR reflectivity spectra (open circles) and best fit calculated (solid lines)-spectra are shifted vertically $30 \%$ for clarity-and b) Kramers-Kronig obtained Im( $(\varepsilon)$ spectra (open circles) and the best fit calculated (solid lines) of PbTe-PbS $8 \%$ and PbTe-PbS $30 \%$ compositions. SS stands for the solid solutions and PS stands for the phase-separated samples. c) Best fit calculated TO phonons contribution to the $\operatorname{Im}(\varepsilon)$ spectra of the PbTe-PbS studied compositions. The increased values of the $\operatorname{Im}\left(\varepsilon_{\text {phonons }}\right)$ spectra in the low frequency range are attributed to the $\approx 32 \mathrm{~cm}^{-1}$ TO phonon mode used in Equation (3) for all the studied samples (for details see text). Symbols refer to the phonon frequencies of the different phases with the latter determined by NMR; $(\bullet) \mathrm{PbTe}_{0.02} \mathrm{~S}_{0.98},(*)$ $\mathrm{PbTe}_{0.93} \mathrm{~S}_{0.07},(\mathrm{O}) \mathrm{PbTe}_{0.6} \mathrm{~S}_{0.4}$, and $(\bullet) \mathrm{PbTe}_{0.8} \mathrm{~S}_{0.2}$. d) Solid lines are the interpolation lines showing the concentration dependence of the optical mode frequencies (TO-LO pairs) of PbTe $1-x$ S mixed crystals. ${ }^{[42]}$ Symbols stand for the analyzed TO frequencies of the PbTe-PbS $8 \%$ and $30 \%$ compositions, solid solutions and phase-separated, with the $x$ values deduced from the NMR results.

optical (TO) phonon modes associated with $\mathrm{Pb}-\mathrm{Te}$ and $\mathrm{Pb}-\mathrm{S}$ vibrations, and are observed in the Kramers-Kronig obtained $\operatorname{Im}(\varepsilon)$ spectra of Figure $7 \mathrm{~b}$. The $\operatorname{Im}(\varepsilon)$ spectra display increased values in the low frequency range denoting free carrier effects which are associated with the reflectivity minima and are expected to occur since our samples exhibit $\mathrm{n}$-type conduction. For the $\mathrm{PbS} 8 \%$ solid-solution, the phonon contribution is screened by the strong free carrier effects, which is associated with a weak feature in the respective $\operatorname{Im}(\varepsilon)$ spectrum in the region of $\approx 155 \mathrm{~cm}^{-1}$. For the two phase-separated samples containing $8 \% \mathrm{PbS}$ and $30 \% \mathrm{PbS}$ there are two clear peaks in the $\operatorname{Im}(\varepsilon)$ spectra located at $\approx 100$ and $\approx 150 \mathrm{~cm}^{-1}$, while for the $\mathrm{PbS} 30 \%$ solid solution there is a strong peak at $\approx 150 \mathrm{~cm}^{-1}$ and a weaker structure in the frequency range $\approx 120-130 \mathrm{~cm}^{-1}$ (Figure $7 \mathrm{~b}$ ).
The experimentally obtained reflectivity spectra were fitted considering phonons and plasmon contributions to the complex dielectric function:

$$
\begin{array}{r}
\varepsilon(\omega)=\varepsilon_{\infty} \prod_{j} \frac{\omega_{\mathrm{LO}, \mathrm{j}}^{2}-\omega^{2}-i \gamma_{\mathrm{LO}, \mathrm{j}} \omega}{\omega_{\mathrm{TO}, \mathrm{j}}^{2}-\omega^{2}-i \gamma_{\mathrm{TO}, \mathrm{j}} \omega} \\
+\frac{\varepsilon_{\infty} \cdot\left(\omega_{P}^{2}-i\left(\gamma_{P}-\gamma_{o}\right) \omega\right)}{-\omega^{2}-i \gamma_{o} \omega}
\end{array}
$$

where $\varepsilon_{\infty}$ is the optical-frequency dielectric constant. The first term of Equation (3) corresponds to the phonon contribution with $\omega_{\mathrm{TO}, j}$ and $\omega_{\mathrm{LO}, j}$ being the TO and LO phonon frequencies and $\gamma_{\mathrm{TO}, j}$ and $\gamma_{\mathrm{LO}, j}$ the phonon damping constants respectively. 
The second term in Equation (3) is the free-carrier term which yields the plasmon contribution with frequency $\omega_{P}$ and a frequency dependent damping constant $\gamma(\omega)$, usually referred to as double damped Drude model or extended Drude model. ${ }^{[43]}$ Using this model, we calculated the reflectivity spectra and KramersKronig obtained $\operatorname{Im}(\varepsilon)$ shown as solid lines in Figure 7a,b, which are in excellent agreement with the experimental data.

In general, the longitudinal optical (LO) vibrational frequencies are the roots of the complex dielectric function $\varepsilon(\omega)$. In the case of composite materials, i.e., materials having more than one phases, the dielectric function depends on the constituents' volume fraction. ${ }^{[44]}$ Dealing with composite materials, the LO modes obtained by Equation (3) are not the pure LO modes of the different components, but their position is a function of the volume fraction. On the other hand, the TO phonon frequencies are independent of the volume fraction. ${ }^{[45]}$ This means that, even if the material is a composite, the TO modes as obtained by Equation (3) are the pure TO phonon modes of the different components in the composite. Since our intention is to attribute the phonon vibrational frequencies to specific compositions in the $\mathrm{PbTe}-\mathrm{PbS}$ studied materials, our discussion on the IR reflectivity results is limited only to the analyzed TO phonon modes of Equation (3).

Figure 7c displays the contribution of the TO phonon modes of the studied compositions to the imaginary part of the complex dielectric function. For the analysis of all the studied compositions a TO mode at $\approx 32 \mathrm{~cm}^{-1}$, though outside our experimental range, was used. The $\mathrm{PbTe}_{1-x} \mathrm{~S}_{x}$ system shows a "two-mode" behavior on the basis of the Random Element Isodisplacement (REI) model which treats the optical phonons of mixed crystals. ${ }^{[42,46]}$ For $\mathrm{PbTe}$ the infrared frequencies are $\omega_{\text {ТО }}=32 \mathrm{~cm}^{-1}$ and $\omega_{\mathrm{LO}}=104 \mathrm{~cm}^{-1}$ while for the PbS the respective frequencies are located at 66 and $216 \mathrm{~cm}^{-1}$. Miljkovič et al. studied the optical properties of $\mathrm{PbTe}_{1-x} \mathrm{~S}_{x}$ mixed crystals for $x=0.02$ and $x=0.05$ and by linear interpolation of their experimental frequencies determined a simplistic optical mode behavior of $\mathrm{PbTe}_{1-x} \mathrm{~S}_{x}$ mixed crystals with $0 \leq x \leq 1$ and their results are displayed as solid lines in Figure $7 \mathrm{~d}^{[42]}$ The optical behavior of the system actually coincides with the class A mode behavior of mixed crystals as determined by the notation of Genzel et al. ${ }^{[47]}$

Our experimental results of the solid-solution materials, the $\mathrm{PbTe}-\mathrm{PbS} 8 \%$ solid solution exhibits two TO modes at $\approx 32$ and $\approx 155 \mathrm{~cm}^{-1}$ (see Figure $7 \mathrm{c}$ ) which confirms that this sample is a solid solution showing normal "two-mode" behavior. For $\mathrm{PbTe}-\mathrm{PbS} 30 \%$, we would expect two observed modes from the simple REI model: one at $\approx 32 \mathrm{~cm}^{-1}$ (which is outside our experimental region) and another $\approx 130 \mathrm{~cm}^{-1}$. However, modes are observed at $\approx 150$ and $\approx 120 \mathrm{~cm}^{-1}$ (Figure $7 \mathrm{c}$ ). These two TO modes may be attributed to different phases present in the sample, each of which having also a low frequency TO mode at $\approx 32 \mathrm{~cm}^{-1}$, suggesting the presence of two phases within the solid-solution $\mathrm{PbTe}-\mathrm{PbS} 30 \%$ sample, in agreement with NMR findings. For the two phase-separated PbTe$\mathrm{PbS} 8 \%$ and $30 \%$ samples, the analyzed TO phonon modes of Figure 7c were found at nearly the same frequency confirming the NMR results for the existence of two phases with approximately the same composition in these phase-separated materials.
The analyzed TO phonon frequencies of the solid solution $\mathrm{PbTe}-\mathrm{PbS}$ materials together with the NMR-obtained alloy compositions are presented in Figure 7d. As can be seen, there is a fairly good agreement between our experimental NMR results and the interpolation lines of Miljkovič et al. ${ }^{[42]}$ For the $\mathrm{PbTe}-\mathrm{PbS} 8 \%$ solid solution, the $\approx 32-155 \mathrm{~cm}^{-1}$ TO modes are attributed to a nearly ideal $\mathrm{PbTe}_{0.92} \mathrm{~S}_{0.08}$ crystal. For the $\mathrm{PbS}$ $30 \%$ solid solution, we find the existence of an additional TO phonon mode of $\approx 32-124 \mathrm{~cm}^{-1}$ in addition to the $\approx 32-151 \mathrm{~cm}^{-1}$ mode, which correspond to NMR-obtained compositions of $\mathrm{PbTe}_{0.6} \mathrm{~S}_{0.4}$ and $\mathrm{PbTe}_{0.8} \mathrm{~S}_{0.2}$, respectively, Figure $7 \mathrm{~d}$. For the two phase-separated samples $\mathrm{PbS} 8 \%$ and $30 \%$, the NMR results yielded $\mathrm{PbTe}_{0.93} \mathrm{~S}_{0.07}$ and $\mathrm{PbTe}_{0.02} \mathrm{~S}_{0.98}$ for the compositions of the two phases which have their TO frequencies at $\approx 32-159 \mathrm{~cm}^{-1}$ and $\approx 32-100 \mathrm{~cm}^{-1}$, respectively. The IR reflectivity results closely agree with the NMR results and confirm that an ideal solid solution is obtained only for the quenched $\mathrm{PbTe}-\mathrm{PbS} 8 \%$ sample, while two-phase behavior is observed for the quenched $\mathrm{PbTe}-\mathrm{PbS}$ 30\% sample.

\section{Conclusions}

For $\mathrm{PbTe}_{1-x} \mathrm{~S}_{x}$ with $x=0.08$ and 0.3 , thermally induced precipitation of large regions of $\mathrm{PbS}$ in a matrix of $\mathrm{PbTe}$ is initiated between 175 and $200{ }^{\circ} \mathrm{C}$, adhering to previous reports of the nucleation of $\mathrm{PbS}$ in PbTe. ${ }^{[23]}$ Magic-angle-spinning ${ }^{125} \mathrm{Te} \mathrm{NMR}$ spectra of $\mathrm{PbTe}-\mathrm{PbS}$ exhibit a series of peaks that enable determination of the composition of quenched and annealed samples with higher accuracy $( \pm 1 \%$ at low $x$ ) than available from the phase diagram, both for the Te-rich and Te-poor phases. On the other hand, minor amounts $(<2 \%)$ of inclusions that can be important for transport properties may escape NMR detection. Incomplete phase separation by nucleation and growth, due to insufficient annealing time, has been detected by NMR for $x$ $=0.16$. An unexpected difference between the effects of linear and of angled Te-Pb-S configurations on ${ }^{125} \mathrm{Te}$ NMR chemical shifts was substantiated by DFT simulations. NMR analysis complemented previous investigations by X-ray scattering and electron-beam methods, which showed $\mathrm{PbS}$ segregation by annealing, but could not easily quantify the amount of the segregated components.

We have shown that $\mathrm{PbTe}-\mathrm{PbS}$ thermoelectric materials may reversibly generate solid-solution alloys and phaseseparated materials depending on the temperature of annealing. However, nearly ideal solid solutions for PbTe-PbS can be obtained by quenching only within the nucleation and growth composition space (i.e., $<\approx 12 \% \mathrm{PbS}$ ). It is essential to note that the as-quenched samples of $\mathrm{PbTe}-\mathrm{PbS} 30 \%$ appear as alloys by synchrotron PXRD from their agreement with Vegard's law, but the local probe nature of NMR and IR spectroscopy reveals that they are actually phase inhomogeneous. This is an indication of nascent spinodal decomposition that will result in nanostructures, as has been observed previously in samples of the same composition. ${ }^{[3]}$ There are a number of so-called solid solution PbTe-based thermoelectric materials that have recently been reported with adherence to Vegard's law from PXRD but also exhibit low lattice thermal conductivities. ${ }^{[4-50]}$ Our findings highlight the importance of careful 
chemical and microstructural analysis of thermoelectric materials; simple powder X-ray diffraction analysis is not sufficient at describing whether a material is truly a solid solution or nanostructured.

\section{Experimental Section}

Synthesis: Samples of PbTe-PbS 4, 8, 16, 30, and 50\% were synthesized using $\mathrm{PbTe}$ and $\mathrm{PbS}$ starting materials prepared using highpurity starting elements (Pb 99.99\% American Elements, Te $99.999 \%$ and S 99.99\% 5N Plus) by first reacting stoichiometric amounts to create $\mathrm{PbTe}$ and $\mathrm{PbS}$ starting materials. These starting materials were reground and reacted in the concentrations mentioned. All reactions were flame sealed in fused silica ampoules at a residual vacuum of $\approx 10^{-4}$ Torr and heated to $1100{ }^{\circ} \mathrm{C}$ in a box furnace. Samples were inverted several times in the liquid state and quenched in water to room temperature. Selected samples were then post-annealed for $72 \mathrm{~h}$ at $500{ }^{\circ} \mathrm{C}$ to assure adequate phase separation for comparison with the rapidly quenched samples.

Scanning Electron Microscopy (SEM): Scanning electron microscopy was performed on finely-polished samples using a FEI Helios Nanolab focused ion beam (FIB)/SEM. Imaging using the electron beam was accomplished at $5 \mathrm{kV}$ voltage with a $98 \mathrm{pA}$ current, while milling using the ion beam was accomplished at $30 \mathrm{kV}$ voltage with $2.8 \mathrm{nA}$ current. Areas of the sample were bombarded with $\mathrm{Ga}^{+}$ions, resulting in preferential etching of the sample along grain boundaries and differing phases. The resulting image provides a clearer representation of the microstructure, with minimized appearance of surface defects and scratches.

High-Resolution Powder X-Ray Diffraction (PXRD): The samples were hand ground using a mortar and pestle and passed through a $60 \mu \mathrm{m}$ steel mesh sieve. The resulting fine powders with grain size $\leq 60 \mu \mathrm{m}$ were packed into $0.3 \mathrm{~mm}$ quartz capillaries and evacuated to a residual vacuum of $\approx 10^{-4}$ Torr and flame-sealed using a high temperature torch. The capillaries were placed in a double-tilt goniometer in transmission geometry (DebyeScherrer method) and rotated at $500 \mathrm{rpm}$. High-resolution X-ray diffraction was performed by synchrotron radiation at Argonne National Laboratory on the Advanced Photon Source (APS), beamline 11-BM using a 12-analyzer $\mathrm{Si}$ detector and calibrated radiation wavelength of $0.412455 \AA \AA^{[51,52]} \mathrm{A}$ calibrated hot air blower (operational temperature room temperature to $1000{ }^{\circ} \mathrm{C}$ accurate to $\pm 5^{\circ}$ ) was situated approximately $5 \mathrm{~mm}$ below the spinning capillary. The small capillary diameter assured an even thermal profile and minimization of X-ray absorption. Rietveld refinements were performed using the GSAS program.

Infrared Reflectivity (IR): Infrared (IR) reflectivity measurements were performed on finely-polished PbTe-PbS samples using a Bruker $113 \mathrm{~V} \mathrm{FTIR}$ spectrometer with a resolution of about $2 \mathrm{~cm}^{-1}$, at nearly normal incidence, in the $90-1000 \mathrm{~cm}^{-1}$ spectral region, at room temperature. The reflection coefficient was determined by a typical sample-in-sample-out method with a mirror as the reference. In nearly normal incidence, the reflectivity is related to the complex dielectric function $\varepsilon(\omega)$ by the relation:

$R(\omega)=\left(\frac{\sqrt{\varepsilon(\omega)}-1}{\sqrt{\varepsilon(\omega)}+1}\right)^{2}$

The experimental reflectivity spectra $R(\omega)$ were analyzed by the Kramers-Kronig (KK) transformation technique to obtain the phase angle between reflected and incident wave. The calculated spectrum of phase angle $\theta(\omega)$ was used with that of $R(\omega)$ to subsequently compute the real and imaginary parts of the complex dielectric function $\varepsilon(\omega)$. The peaks of the resulting $\operatorname{Im}(\varepsilon)$ spectra are associated with the frequencies of the transverse (TO) modes.

Nuclear Magnetic Resonance (NMR): ${ }^{125}$ Te nuclear magnetic resonance (NMR) experiments were performed at $126 \mathrm{MHz}$ using a Bruker Biospin (Billerica, MA) DSX-400 spectrometer (magnetic field of $9.39 \mathrm{~T}$ ). The coarsely powdered samples were packed into $2.5-\mathrm{mm}$ zirconia rotors and rotated at $22 \mathrm{kHz}$ in a magic-angle-spinning probe head (Bruker), which narrowed the lines significantly. The $\pi / 2$ pulse length was $2.5 \mu \mathrm{s}$. Signals were detected after a Hahn echo generated by a $\pi / 2-t_{\mathrm{r}}-\pi-t_{\mathrm{r}}$ two-pulse sequence, where $t_{r}$ denotes a rotation period. Measuring times generally ranged between 15 and $24 \mathrm{~h}$ per spectrum, except for spectra to detect Te dispersed in $\mathrm{PbTe}$, which required 2.5 days. In order to minimize distortion of relative peak intensities by the pulse excitation bandwidth, spectra with peaks separated by more than $90 \mathrm{kHz}$ were measured as composites, with carrier frequencies separated by $50 \mathrm{kHz}$. ${ }^{125} \mathrm{Te} \mathrm{NMR}$ chemical shifts were referenced to $\mathrm{Te}(\mathrm{OH})_{6}$ in solution, using solid $\mathrm{TeO}_{2}$ at $+750 \mathrm{ppm}$ as a secondary reference. The longitudinal $\left(\mathrm{T}_{1}\right)$ relaxation times of the observed peaks were similar, between 1.5 and $2.5 \mathrm{~s}$; the peak near the PbTe resonance position had a slightly longer $T_{1}$ than the other signals in both annealed and low-x quenched samples. The spectra shown were recorded with recycle delays of 3 or $10 \mathrm{~s} .{ }^{207} \mathrm{~Pb}$ NMR spectra were also measured but did not exhibit resolved peaks that provided interesting information.

Density Functional Theory (DFT) Calculations of Chemical Shifts: All geometry optimizations and NMR chemical shift calculations were performed using plane wave density functional theory (DFT) employing a Perdew-Burke-Ernzehof (PBE) functional and pseudopotentials generated on-the-fly, using CASTEP and CASTEP NMR programs (Accelrys Software Inc.). ${ }^{[33]}$ An energy cutoff of $550 \mathrm{eV}$ was used along with the exact representation of the electron density. We studied two sizes of PbTe unit cells with a single Te atom substituted by a $\mathrm{S}$ atom. The smaller, 64-atom unit cell of $\mathrm{PbTe}_{0.97} \mathrm{~S}_{0.03}$ adopts $\mathrm{Pm} \overline{3} \mathrm{~m}$ symmetry and was done on a Mokhorst-Pack grid of $7 \times 7 \times 7$ k-points. The larger, 128 atom unit cell of $\mathrm{PbTe}_{0.98} \mathrm{~S}_{0.02}$ was studied in $\mathrm{P} 4 / \mathrm{mmm}$ symmetry and on a Mokhorst-Pack grid of $8 \times 8 \times 4 k$-points. Geometry optimizations were conducted with the following criteria: convergence of $5 \times 10^{-6} \mathrm{eV} /$ atom energy, maximum force of $0.01 \mathrm{eV} / \AA$, maximum stress of $0.02 \mathrm{GPa}$, and maximum displacement of $5 \times 10^{-4} \AA$. The results were visualized using Materials Studio (Accelrys Software Inc.). ${ }^{[53]}$

\section{Supporting Information}

Supporting Information is available from the Wiley Online Library or from the author.

\section{Acknowledgements}

S.N.G. and M.G.K. thank the Revolutionary Materials for Solid State Energy Conversion, an Energy Frontier Research Center funded by the U.S. Department of Energy, Office of Science, Office of Basic Energy Sciences under Award Number DE-SC0001054, for primary funding. The SEM work was performed in the EPIC facility of the NUANCE Center at Northwestern University. The NUANCE Center is supported by NSF-NSEC, NSF-MRSEC, Keck Foundation, the State of Illinois, and Northwestern University. Use of the Advanced Photon Source at Argonne National Laboratory was supported by the U. S. Department of Energy, Office of Science, Office of Basic Energy Sciences, under Contract No. DE-AC02-06CH11357. NMR characterization by K.S.R., B.N., E.M.L., and A.R. was supported by the U.S. Department of Energy, Office of Basic Energy Science, Division of Materials Sciences and Engineering, at the Ames Laboratory, which is operated for the U.S. Department of Energy by lowa State University under Contract No. DE-AC02-07CH11358.

Received: July 12, 2012 Published online:

[1] M. G. Kanatzidis, Chem. Mater. 2009, 22, 648.

[2] G. J. Snyder, E. S. Toberer, Nat. Mater. 2008, 7, 105.

[3] C. J. Vineis, A. Shakouri, A. Majumdar, M. G. Kanatzidis, Adv. Mater. 2010, 22, 3970.

[4] J. R. Sootsman, D. Y. Chung, M. G. Kanatzidis, Angew. Chem. Int. Ed. 2009, 48, 8616.

[5] J. R. Szczech, J. M. Higgins, S. Jin, J. Mater. Chem. 2011, 21, 4037. 
[6] S.-M. Lee, D. G. Cahill, R. Venkatasubramanian, Appl. Phys. Lett. 1997, 70, 2957.

[7] R. Venkatasubramanian, E. Siivola, T. Colpitts, B. O'Quinn, Nature 2001, 413, 597

[8] A. I. Hochbaum, R. Chen, R. D. Delgado, W. Liang, E. C. Garnett, M. Najarian, A. Majumdar, P. Yang, Nature 2008, 451, 163.

[9] D. Li, Y. Wu, R. Fan, P. Yang, A. Majumdar, Appl. Phys. Lett. 2003 $83,3186$.

[10] K. F. Hsu, S. Loo, F. Guo, W. Chen, J. S. Dyck, C. Uher, T. Hogan, E. K. Polychroniadis, M. C. Kanatzidis, Science 2004, 303, 818.

[11] T. Ikeda, V. A. Ravi, G. J. Snyder, Acta Mater. 2009, 57, 666

[12] J. D. Sugar, D. L. Medlin, J. Alloys Compd. 2009, 478, 75.

[13] Y. Pei, J. Lensch-Falk, E. S. Toberer, D. L. Medlin, G. J. Snyder, Adv. Funct. Mater. 2011, 21, 241.

[14] Y. Gelbstein, O. Ben-Yehuda, E. Pinhas, T. Edrei, Y. Sadia, Z. Dashevsky, M. Dariel, J. Electron. Mater. 2009, 38, 1478.

[15] S. Gorsse, P. Bauer Pereira, R. Decourt, E. Sellier, Chem. Mater. 2009, 22, 988

[16] J. Androulakis, C.-H. Lin, H.-J. Kong, C. Uher, C.-I. Wu, T. Hogan, B. A. Cook, T. Caillat, K. M. Paraskevopoulos, M. G. Kanatzidis, J. Am. Chem. Soc. 2007, 129, 9780.

[17] J. R. Sootsman, J. He, V. P. Dravid, C.-P. Li, C. Uher, M. G. Kanatzidis, J. Appl. Phys. 2009, 105, 083718.

[18] J. R. Sootsman, J. He, V. P. Dravid, S. Ballikaya, D. Vermeulen C. Uher, M. G. Kanatzidis, Chem. Mater. 2009, 22, 869.

[19] T. Ikeda, E. S. Toberer, V. A. Ravi, G. Jeffrey Snyder, S. Aoyagi, E. Nishibori, M. Sakata, Scripta Mater. 2009, 60, 321.

[20] H. J. Wu, S. W. Chen, T. Ikeda, G. J. Snyder, Acta Mater. 2012, 60, 1129.

[21] J. R. Sootsman, R. J. Pcionek, H. Kong, C. Uher, M. G. Kanatzidis, Chem. Mater. 2006, 18, 4993.

[22] J. R. Sootsman, H. Kong, C. Uher, J. J. D’Angelo, C. I. Wu, T. P. Hogan, T. Caillat, M. G. Kanatzidis, Angew. Chem. Int. Ed. 2008, $47,8618$.

[23] S. N. Girard, J. He, C. Li, S. Moses, G. Wang, C. Uher, V. P. Dravid, M. G. Kanatzidis, Nano Lett. 2010, 10, 2825.

[24] S. N. Girard, J. He, X. Zhou, D. Shoemaker, C. M. Jaworski, C. Uher, V. P. Dravid, J. P. Heremans, M. G. Kanatzidis, J. Am. Chem. Soc. 2011, 133, 16588.

[25] M. S. Darrow, W. B. White, R. Roy, Trans. Metall. Soc. AIME 1966 $236,654$.

[26] M. S. Darrow, W. B. White, R. Roy, Mater. Sci. Eng. 1969, 3, 289.

[27] A. Volykhov, L. Yashina, V. Shtanov, Inorg. Mater. 2006, 42, 596.

[28] A. Volykhov, L. Yashina, M. Tamm, A. Ryzhenkov, Inorg. Mater. 2009, 45, 968.

[29] V. Leute, N. Volkmer, Z. Phys. Chem 1985, 144, 145.

[30] J. D. Gunton, M. Droz, Introduction to the Theory of Metastable and Unstable States, Vol. 183, Springer-Verlag, Berlin 1983.
[31] T. Ikeda, L. A. Collins, V. A. Ravi, F. S. Gascoin, S. M. Haile, G. J. Snyder, Chem. Mater. 2007, 19, 763.

[32] T. Ikeda, N. J. Marolf, K. Bergum, M. B. Toussaint, N. A. Heinz V. A. Ravi, G. Jeffrey Snyder, Acta Mater. 2011, 59, 2679.

[33] E. Quarez, K. F. Hsu, R. Pcionek, N. Frangis, E. K. Polychroniadis, M. G. Kanatzidis, J. Am. Chem. Soc. 2005, 127, 9177.

[34] J. He, S. N. Girard, M. G. Kanatzidis, V. P. Dravid, Adv. Funct. Mater 2010, 20, 764

[35] E. M. Levin, B. A. Cook, K. Ahn, M. G. Kanatzidis, K. Schmidt-Rohr, Phys. Rev. B 2009, 80, 115211

[36] C. M. Jaworski, J. Tobola, E. M. Levin, K. Schmidt-Rohr J. P. Heremans, Phys. Rev. B 2009, 80, 125208.

[37] M. N. Alexander, P. L. Sagalyn, S. D. Senturia, C. R. Hewes, J. Nonmet. 1973, 1, 251.

[38] M. D. Nielsen, E. M. Levin, C. M. Jaworski, K. Schmidt-Rohr, J. P. Heremans, Phys. Rev. B 2012, 85, 045210.

[39] K. Beshah, D. Zamir, P. Becla, P. A. Wolff, R. G. Griffin, Phys. Rev. B $1987,36,6420$.

[40] H. Lin, E. S. Bozcaronin, S. J. L. Billinge, J. Androulakis C. D. Malliakas, C. H. Lin, M. G. Kanatzidis, Phys. Rev. B 2009, 80, 045204.

[41] S. D. Senturia, A. C. Smith, C. R. Hewes, J. A. Hofmann, P. L. Sagalyn, Phys. Rev. B 1970, 1, 4045.

[42] J. M. Miljković, N. Romčević, Z. V. Popovic, W. Köunig, V. N. Nikiforov, Phys. Status Solidi B 1996, 193, 43.

[43] F. Gervais, Mater. Sci. Eng., R 2002, 39, 29.

[44] G. A. Niklasson, C. G. Granqvist, O. Hunderi, Appl. Opt. 1981, 20, 26.

[45] S. A. FitzGerald, T. W. Noh, A. J. Sievers, L. A. Xue, Y. Tzou, Phys. Rev. B 1990, 42, 5469.

[46] N. Romčević, J. Trajić, M. Romčević, A. Golubović, S. Nikolić, V. N. Nikiforov, J. Alloys Compd. 2005, 387, 24.

[47] L. Genzel, T. P. Martin, C. H. Perry, Phys. Status Solidi B 1974, 62, 83.

[48] Y. Pei, X. Shi, A. LaLonde, H. Wang, L. Chen, G. J. Snyder, Nature 2011, 473, 66

[49] H. Wang, Y. Pei, A. D. LaLonde, G. J. Snyder, Adv. Mater. 2011, 23, 1366.

[50] Y. Pei, A. LaLonde, S. Iwanaga, G. J. Snyder, Energy Environ. Sci. 2011.

[51] P. L. Lee, D. Shu, M. Ramanathan, C. Preissner, J. Wang, M. A. Beno, R. B. Von Dreele, L. Ribaud, C. Kurtz, S. M. Antao, X. Jiao, B. H. Toby, J. Synchrotron Radiat. 2008, 15, 427.

[52] J. Wang, B. H. Toby, P. L. Lee, L. Ribaud, S. M. Antao, C. Kurtz, M. Ramanathan, R. B. V. Dreele, M. A. Beno, Rev. Sci. Instrum. 2008 79, 085105.

[53] S. J. Clark, M. D. Segall, C. J. Pickard, P. J. Hasnip, M. I. J. Probert K. Refson, M. C. Payne, Z. Kristallogr. 2005, 220, 567. 